\title{
Enhancement of Antenna Parameters of a Rectangular MSA with Optimized Inset Fed Using HFSS
}

\author{
${ }^{* 1}$ Basheer Ali Sheik, ${ }^{2}$ Dr. P V Sridevi and ${ }^{3}$ Dr. P V Rama Raju \\ ${ }^{* 1}$ Research Scholar, Department Of Electronics and Communication Engineering, Andhra University College of \\ Engineering (A), Visakhapatnam, Andhra Pradesh, India, ${ }^{2}$ Professor, Department Of Electronics And Communication \\ Engineering, Andhra University College of Engineering(A),Visakhapatnam, Andhra Pradesh, India, ${ }^{3}$ Professor \& HOD, \\ Department of ECE, SRKR Engineering College(A), Bhimavaram, Andhra Pradesh, India.
}

Email: basheeralis@yahoo.com

\section{Received: 06th October 2017 Accepted: 14th November 2017, Published: 31st December 2017}

\begin{abstract}
Microstrip Antenna (MSA) plays a very important role in wireless communication systems (such as Mobile \& Satellite Communications, Military applications, WLAN and Internet of Things (IoT)). The MSA has a compactable nature in design of antennas in wireless systems such as miniaturized size, easy to fabrication, low weight and low cost. But it has limitations too; those are narrowband, low gain, low directivity, and high cross polarization in H-plane due to impedance mismatching between high input impedance of patch at edge and low impedance of feed line (transmission line). This problem can be overcome with bring down the input impedance of patch to use shorting pins, different EBG structures, and different optimized feed methods. In this paper is going to reduce impedance mismatch with newly proposed formulas for inset fed method. This will go to be enhancing the antenna parameters and to improve the uniform distribution of current density on patch with diminishing the inductive load at junction of patch and feed line. Finally new optimized formulas for depth and gap of inset fed will be defined by iterative process in HFSS 14v. It yields the best and optimized results of antenna parameters in given frequency of operation, height of the substrate and dielectric constant.
\end{abstract}

Keywords: Inset Feed, Depth of Notch, Gap of Notch, Directivity, Cross-Polarization and HFSS

\section{Introduction}

MSA has been in any shape (Tree, human body, square, rectangular, circular, trapezoidal, elliptical, etc.). The most popular MSA shape is rectangular shape, because it's very easy to design, analyze and fabricate compared to other shapes of patch. MSA has been excited with different feed methods (such as edge fed, inset-fed, coaxial fed (or probe fed), proximity and aperture coupling) [1] - [3]. The impedance mismatching occurred at junction of feed line and patch edge, this degrade the performance of MSA [4]-[11]. To overcome this problem with shorting pins, EBG (Electro-magnetic Band Gap) design structures and optimized feeding methods. These techniques are to concentrate on diminishing input impedance of patch and/or find where the impedance on patch is low to join the feed line at there. The shorting pins used to decrease the inductance between patch and ground. So these are used to improve the performance of antenna and have low crosspolarization due to paired pins [12]. But this model has a drawback, which is not applicable in design of array of antennas due to increasing the design problems such as danged the substrate while drilling for insetting pins and manufacturing cost become huge.

The next method to go for diminishing the impedance mismatching between patch and feed is using EBG structure on MSA. This is very effective method to improve the antenna parameters. This is three types of structures; those are 1D, 2D and 3D [13]-[17]. But these are more costly for complicated design.

So next method to go for reduce impedance mismatch between patch and feed is using an optimized feed method. We have five methods to feed (excite) the patch. In their, inset fed is more popular to simple design, give better results especially in array feed network and low cost. Based on these advantages, this paper is going to design optimized inset fed. Before going to optimized design of inset fed, here go to discuss some basics of inset fed. The inset fed means, the feed line is not join the edge of patch. The feed line inset is into the patch and join where the patch impedance is nearly equal to feed line impedance. Inset fed depends on depth and gap of notch (shown in Fig. 1). These two are mainly depended on length of patch, operating frequency, and height or thickness of substrate. Depth means how much the feed line inset into the patch. To determine the location of depth based on current distribution on patch, which is like cosine square function. The maximum current distribution is center of patch and electric field is zero. I.e., the impedance is minimum (气zero) at center and maximum at edge of patch. The gap is mostly useful for separate/isolate the feed line from patch, and to develop some amount of capacitance for reduce inductive load of patch [18]-[24]. Whatever the advantages of inset fed, it has drawbacks too. The drawbacks are high cross polarization in H-plane due to unbalancing of current distribution at junction of patch and feed line and become 
complicate to design at higher frequencies due to increasing of width of feed line. But these formulas of depth and gap defined complicatedly so far. To avoid that problem and get best results with newly proposed formulas for depth and gap of notch, and improve the antenna parameters and low cross polarization.

The aim of this paper is trying to develop of empirical expressions to gap and depth of notch for enhancing the antenna parameters of the rectangular micro strip antenna. The optimized depth and gap of notch can be generated internal capacitance that will be compensating the inductive load and reducing/dwindling the impedance mismatch between the patch and feed line, and the current density distribution on patch is also uniform, which is dwindling cross-polarization. The design and simulation had done on Ansoft HFSS v14.

\section{Design Procedure of MSA}

The MSA design requires dimensions of patch and ground, and substrate material. This paper is taking the rectangular shape as patch, various materials for substrate and various frequencies. To determine the dimensions of the rectangular patch, ground and inset fed (conventional) are using from Eq. 1 to Eq. 8. These formulas defined below [1]-[3] \& [18]-[24]. The design of rectangular MSA has been shown below in Fig. 1. HFSS is going to design and simulate the MSA.

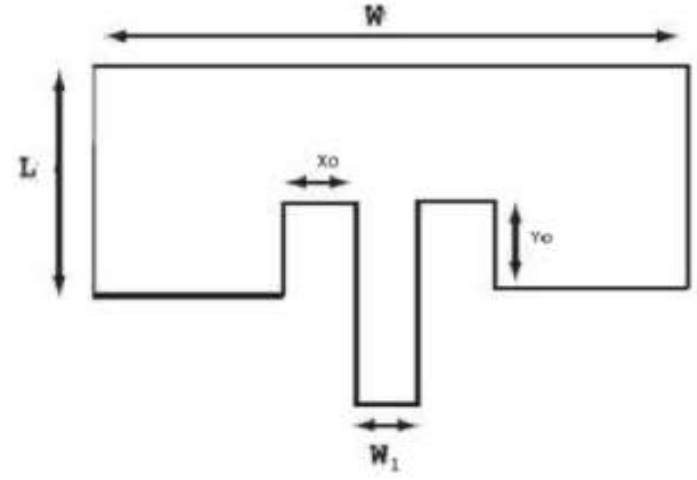

Fig.1: The rectangular patch with inset fed.

Where $\mathrm{L}$ is length of the patch, $\mathrm{W}$ is the width of the patch, Xo is the gap of notch, Yo is the depth of notch and $\mathrm{W}_{1}$ is the width of feed line. These parameters are shown above in Fig. 1.

\section{Design Equations:}

The patch antenna with inset feed design rules can be presented below [1]-[3] \& [18]-[24]. Where 'c' is velocity of electromagnetic field, $f_{0}(\mathrm{GHz})$ is operating frequency, $\varepsilon_{y}(\mathrm{~F} / \mathrm{m})$ is relative dielectric constant, $z_{0}(\Omega)$ is impedance of transmission line and $R_{\text {in }}(\Omega)$ is input impedance of patch.

1) The height of substrate $(\mathrm{H})$ is given as:

$$
H=\frac{c}{12.56 f_{0} \sqrt{\varepsilon_{T}}} \text {. }[\mathrm{mm}]
$$

$$
W=\frac{C}{f_{0} \sqrt{2\left\lfloor\varepsilon_{v}+\mathbb{1}\right)}} \quad[\mathrm{mm}]
$$

3) The expression for effective dielectric $\left(\varepsilon_{\text {eff }}\right)$ is given as:

$$
\varepsilon_{\text {eff }}=\frac{\left[\varepsilon_{v}+1\right)}{2}+\frac{\left[\varepsilon_{v}-1\right)}{2 \sqrt{1+\frac{12 W}{W}}}[\mathrm{~F} / \mathrm{m}]
$$

4) The patch along length is extending on each end by a distance $\Delta \mathrm{L}$ due fringing fields effect, given as:

$\nabla L=0.412 H \frac{\left(\varepsilon_{\text {aff }}+0.3\right)\left(\frac{W}{H}+0.264\right)}{\left(\varepsilon_{\text {geff }}-0.258\right)\left(\frac{W}{H}+0.8\right)}[\mathrm{mm}]$

5) The effective length of the patch $L_{e f}$ :

$$
L_{\text {eff }}=\frac{c}{2 f_{0, \sqrt{\varepsilon_{\text {eff }}}}} \quad[\mathrm{mm}]
$$

6) For a given operating frequency $f_{0}$, the length of patch is given by as:

$$
\mathrm{L}=L_{\text {eff }}-2 \nabla L[\mathrm{~mm}]
$$

7) Conventional Formulas for Depth and Gap for Inset Fed method [18]-[24],
I. Depth of Notch $(\mathrm{Yo})=\frac{L}{\pi} \cos ^{-1}\left(\sqrt{\frac{z_{0}}{R_{\text {in }}}}\right)[\mathrm{mm}](7)$
II. Gap of Notch $(\mathrm{Xo})=\frac{4,65 \times 10^{-12} C}{f_{0_{\sqrt{2}}} \sqrt{2\left(\varepsilon_{\text {reff }}\right)}}[\mathrm{mm}]$

8) The length and width of ground formulas:
I. $\mathrm{L}_{\mathrm{g}}=\mathrm{L}+6 \mathrm{H}$
[mm]
II. $\mathrm{W}_{\mathrm{g}}=\mathrm{W}+6 \mathrm{H} \quad[\mathrm{mm}]$

9) Defined optimized formulas of Depth and Gap for Inset Fed method:

The formulas for depth and gap of notch in inset fed are to be defined by applying iterative process in HFSS software. The rectangular MSA is simulated with different depths and gaps of inset fed (iterative process or optimization method in HFSS). In their, which one give better results compared to conventional formula those are analyzed and finalized the formulas for depth and gap of notch. All the best results of depths and gaps are tabulated in Table-1. That is shown in below. The optimized formulas are to get analyzing the table-1.

\section{Derivation of Proposed Equations:}

The height of substrate defined as [1], $0.003 \hbar_{0} \leq \mathrm{H} \leq 0.05{h_{0}}$

By experimental analysis, the height of the substrate [22] is,

$$
H=\frac{c}{12.56 f_{6} \sqrt{\varepsilon_{T}}}
$$

Modifying the equation (ii), then resonant frequency is,

$$
f_{0}=\frac{c}{12.56 \mathrm{H} \sqrt{\varepsilon_{T}}}
$$

From Eq. (2), The width of patch

2) The width of patch , $W$ is given as: 
Helix Vol. 8(1): 2633- 2639

$$
W=\frac{c}{f_{0} \sqrt{2\left(\varepsilon_{v}+1\right)}}
$$

Equation (iii) substituted in equation (iv), then modified width of the patch is,

$$
\begin{gathered}
W=\frac{c}{\frac{L}{12.5 \mathrm{E} W \sqrt{\varepsilon_{V}}} \sqrt{2\left(\varepsilon_{v}+1\right)}}=12.5 H \sqrt{\frac{\varepsilon_{V}}{\left.2 \llbracket \varepsilon_{v}+1\right)}} \\
\therefore W=8.84 H \sqrt{\frac{\varepsilon_{v}}{\varepsilon_{v}+1}} .
\end{gathered}
$$

\begin{tabular}{|c|c|c|c|c|c|c|c|c|c|c|c|c|c|}
\hline S.No & $\begin{array}{l}\text { Fr } \\
\text { (GH } \\
\text { Z) }\end{array}$ & $\begin{array}{l}\mathbf{L} \\
(\mathbf{m m})\end{array}$ & $\begin{array}{l}\text { W } \\
(\mathbf{m m})\end{array}$ & $\begin{array}{l}\text { GAP } \\
(\mathbf{m m}) \\
\text { Xo }\end{array}$ & $\begin{array}{l}\text { DEPTH } \\
(\mathrm{mm}) \\
\text { Yo }\end{array}$ & $\begin{array}{l}\text { S11 } \\
\text { (dB) }\end{array}$ & $\begin{array}{l}\text { VSWR } \\
\text { (dB) }\end{array}$ & $\begin{array}{l}\text { E-field } \\
\text { (dB) }\end{array}$ & $\begin{array}{l}\text { Gain } \\
\text { (dB) }\end{array}$ & $\begin{array}{l}\text { Dire } \\
\text { ctivity } \\
\text { (dB) }\end{array}$ & $\frac{L}{V o}$ & $\frac{W}{X o}$ & METHOD \\
\hline \multirow[b]{2}{*}{1.} & 3 & 22.32 & 30.42 & 0.16 & 8.24 & -17.85 & 4.04 & 22.35 & 5.32 & 7.08 & 2.70 & 179.8 & Conventional \\
\hline & 3 & 22.32 & 30.42 & 1.32 & 7.44 & -23.86 & 1.11 & 22.67 & 5.36 & 7.09 & 3 & 23 & zation \\
\hline \multirow[b]{2}{*}{2.} & 6 & 11.16 & 15.21 & 0.08 & 4.12 & -10.38 & 5.42 & 22.16 & 5.27 & 7.04 & 2.70 & 179.8 & ntional \\
\hline & 6 & 11.16 & 15.21 & 0.98 & 3.98 & -41.71 & 4.5 & 22.78 & 5.42 & 7.13 & 2.80 & 15.52 & Optimization \\
\hline \multirow{2}{*}{3.} & 8 & 8.37 & 11.41 & 0.06 & 3.09 & -9.22 & 6.26 & 22.05 & 5.23 & 7.03 & 2.70 & 179.6 & ional \\
\hline & 8 & 8.37 & 11.41 & 0.49 & 2.791 & -32.84 & 0.39 & 22.86 & 5.37 & 7.05 & 3 & 23 & Optimization \\
\hline \multirow{2}{*}{4.} & 9 & 7.44 & 10.14 & 0.05 & 2.74 & -9.8 & 5.8 & 22.06 & 5.18 & 6.99 & 48.7 & 179.8 & Conventional \\
\hline & 9 & 7.44 & 10.14 & 0.44 & 2.48 & -41.68 & 0.14 & 22.84 & 5.38 & 7.06 & 3 & 23 & Optimization \\
\hline \multirow{2}{*}{5.} & 10 & 6.69 & 9.12 & 0.05 & 2.47 & -8.73 & 6.66 & 22.06 & 5.23 & 6.97 & 2.70 & 179.6 & Conventional \\
\hline & 10 & 6.69 & 9.12 & 0.18 & 2.55 & -42.65 & 0.12 & 22.94 & 5.41 & 7.14 & 2.62 & 50.15 & Optimization \\
\hline \multirow{2}{*}{6.} & 12 & 5.58 & 7.60 & 0.152 & 2.23 & -21.53 & 1.45 & 23.01 & 5.44 & 7.13 & 2.50 & 50.04 & Conventional \\
\hline & 12 & 5.58 & 7.60 & 0.38 & 1.86 & -30.37 & 0.52 & 23 & 5.38 & 7.04 & 3 & 20 & Optimization \\
\hline \multirow{2}{*}{7.} & 15 & 4.46 & 6.08 & 0.12 & 1.78 & -28.48 & 0.65 & 23.09 & 5.44 & 7.12 & 2.50 & 50.71 & Conventional \\
\hline & 15 & 4.46 & 6.08 & 0.30 & 1.48 & -30 & 0.51 & 22.98 & 5.33 & 6.97 & 3 & 20 & Optimization \\
\hline \multirow{2}{*}{8.} & 18 & 3.72 & 5.07 & 0.10 & 1.48 & -28.6 & 0.64 & 23.01 & 5.45 & 7.11 & 2.51 & 50.21 & Conventional \\
\hline & 18 & 3.72 & 5.07 & 0.25 & 1.24 & -40.8 & 0.17 & 22.95 & 5.33 & 7.02 & 3 & 20 & Optimization \\
\hline
\end{tabular}

Table-1: The simulated results comparison of conventional and optimization methods using HFSS. 
By Simulations were performed on inset-fed patches with varying substrate thicknesses $h$, notch gap and inset depths .this paper got a relation between gap of inset fed and width of patch(aspect ratio $\left(\frac{W}{g a p}\right)$ ). The critical values of aspect ratio are 22.9 for less than or equal to $10 \mathrm{GHz}$ and 20 for greater than $10 \mathrm{GHz}$ (from Table-1). That is given below

$$
\frac{W}{\text { gap }}=\left\{\begin{array}{cc}
22.9 & f_{0} \leq 10 \mathrm{GHz} \\
20 & f_{0}>10 \mathrm{GHz}
\end{array}\right.
$$

(vi)

For below/or equal to 10GHz:

Combining equations (v) and (vi), then

$$
\begin{gathered}
\text { Gap }=\frac{\frac{8.84 H}{\sqrt{\frac{\varepsilon_{T}}{\varepsilon_{T}+1}}}}{222.9} \\
\therefore \mathrm{Gap}=0.386 \mathrm{H} \sqrt{\frac{\varepsilon_{T}}{\varepsilon_{v}+1}}
\end{gathered}
$$

(vii)

\section{For above 10GHz:}

$$
\begin{aligned}
& \mathrm{Gap}=\frac{\frac{8.04 H}{\sqrt{\frac{\varepsilon_{T}}{\varepsilon_{T}+1}}}}{20} \\
& \therefore \mathrm{Gap}=0.444 \mathrm{H} \sqrt{\frac{\varepsilon_{T}}{\varepsilon_{T}+1}}
\end{aligned}
$$

(viii)

Finally simplified formulas for inset fed by experimental analysis

$$
\text { Depth= L/3 [mm] }
$$

$$
\mathrm{Gap}=\mathrm{K} * \mathrm{H} * \sqrt{\frac{\varepsilon_{v}}{\varepsilon_{v}+1}}[\mathrm{~mm}]
$$

Where $\mathrm{K}$ is constant, depend on resonant frequency.

$$
\mathrm{K}= \begin{cases}0.386 & f_{0} \leq 10 \mathrm{GHz} \\ 0.444 & f_{0}>10 \mathrm{GHz}\end{cases}
$$

This $\mathrm{K}$ value is defined with various experiments. Finally concluded $\mathrm{K}$ with 0.386 for less than/equal to $10 \mathrm{GHz}, 0.444$ for greater than $10 \mathrm{GHz}$ of operating frequency of patch. The simulation and optimization results are tabulated above (Table.1) for analyzing the new formulas from that Table-1.

\section{Results and Discussion}

This paper is going to be analyzed and the performance of new formulas (Eq. 11 and Eq. 12) in different cases that can be observed below. The rectangular patch with optimized inset fed is designed and simulate with HFSS. Note: ' $D_{c}$ ' is Directivity of antenna with Conventional formulas and ' $D_{n}$ ' is Directivity of antenna with newly proposed formulas.
Case I: Variable frequencies:

a) Height of Substrate $(\mathrm{H})=1.5 \mathrm{~mm}$ (constant).

b) Dielectric constant for substrate $\left(\varepsilon_{y}\right)=4.4$.

c) Operating frequency $\left(f_{0}\right)$ is in the range from $3 \mathrm{GHz}$ to $15 \mathrm{GHz}$.

Case-I study, gives that the better directivity of Optimized inset than conventional. But going to high frequency the directivity value decreased. The reason is, going to high frequency but constant height which Table.2: Frequency vs Directivity.

\begin{tabular}{|l|l|l|l|}
\hline S.NO & $f_{\text {L }}(\mathbf{G H Z})$ & $\mathrm{D}_{\mathrm{c}}(\mathbf{d B})$ & $\mathrm{D}_{\mathrm{n}}(\mathbf{d B})$ \\
\hline 1 & 3 & 5.63 & 5.75 \\
\hline 2 & 6 & 6.87 & 7.09 \\
\hline 3 & 9 & 6.49 & 6.69 \\
\hline 4 & 12 & 6.37 & 6.29 \\
\hline 5 & 15 & 7.5 & 7.77 \\
\hline
\end{tabular}

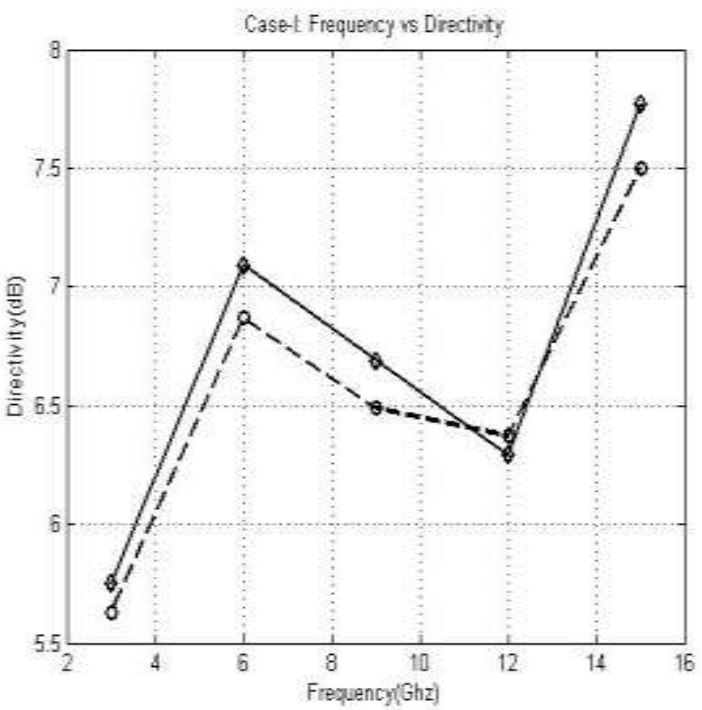

Fig.2: The Comparison of Directivities for various frequencies. increased the surface waves and decreased the fringing field lines strength. This completely represent in tabular and graphically in the Table- 2 and Fig.2 respectively.

\section{Case II: Variable Height:}

a) Operating frequency $\left(f_{o}\right)=6 \mathrm{GHz}$.

b) Dielectric constant for substrate $\left(\varepsilon_{r}\right)=4.4$.

c) Height of Substrate $(\mathrm{H})$ is the range from $1 \mathrm{~mm}$ to $3.6 \mathrm{~mm}$

Case-II study, gives that the better directivity of Optimized inset than conventional. But the directivity value decreased is promotional to increasing of height. The reason is, going to high height but constant frequency. Which is increased the surface waves and decreased the fringing field lines strength. This completely represent in tabular and graphically in the table. 3 and fig. 3 respectively. 
Case III: Variable Dielectric constant of substrate:

a) Operating frequency $\left(f_{0}\right)=6 \mathrm{GHz}$.

b) Height of Substrate $(\mathrm{H})=1.5 \mathrm{~mm}$ (constant). Table.3: Height of substrate vs Directivity.

\begin{tabular}{|l|l|l|l|}
\hline S.NO & $\mathbf{H}(\mathbf{m m})$ & $\mathrm{D}_{\mathrm{c}}(\mathbf{d B})$ & $\mathrm{D}_{\mathrm{n}}(\mathbf{d B})$ \\
\hline 1 & 1 & 6.25 & 6.37 \\
\hline 2 & 1.6 & 6.87 & 7.09 \\
\hline 3 & 2 & 6.46 & 7.03 \\
\hline 4 & 3 & 6.88 & 6.84 \\
\hline 5 & 3.6 & 6.4 & 6.4 \\
\hline
\end{tabular}

Table.4: Dielectric constant vs Directivity.

\begin{tabular}{|l|l|l|l|}
\hline S.NO & $\boldsymbol{\varepsilon}_{\boldsymbol{F}}$ & $\mathrm{D}_{\mathrm{c}}(\mathbf{d B})$ & $\mathrm{D}_{\mathrm{n}}(\mathbf{d B})$ \\
\hline 1 & 2.2 & 7.48 & 7.57 \\
\hline 2 & 3.2 & 7.13 & 7.38 \\
\hline 3 & 4.4 & 6.87 & 7.09 \\
\hline 4 & 5.7 & 6.72 & 6.97 \\
\hline 5 & 9.8 & 5.56 & 5.58 \\
\hline
\end{tabular}

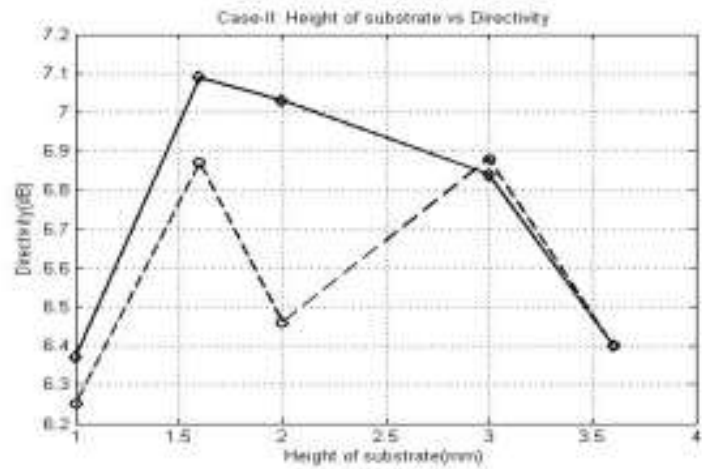

Fig.3: The Comparison of Directivities for various heights of substrate.

c) Dielectric constant for substrate $\left(\varepsilon_{r}\right)$ is in the range of 2.2 to 9.8 .

Case-III study, gives that the better directivity of Optimized inset than conventional. But the directivity value decreased is promotional to increasing of dielectric constant of substrate. The reason is, going to high dielectric constant but constant frequency and height. Which are decreased the fringing field lines strength. This completely represent in tabular and graphically in the table. 4 and fig. 4 respectively.

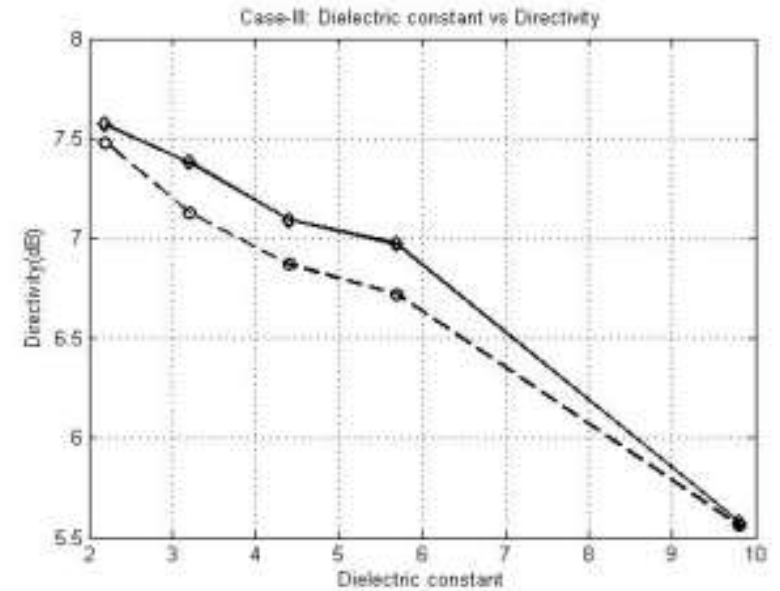

Fig.4: The Comparison of Directivities for various Dielectric constants for substrate.

Case IV: All variables (Frequency, Height and dielectric constant):

a) Dielectric constant for substrate $\left(\varepsilon_{r}\right)$ is in the range from 2.2 to 6 .

b) Height of Substrate $(\mathrm{H})$ is the range from $0.75 \mathrm{~mm}$ to $3.9 \mathrm{~mm}$.

c) Operating Frequency $\left(f_{0}\right)$ is in the range from 3 $\mathrm{GHz}$ to $15 \mathrm{GHz}$.

\begin{tabular}{|l|l|l|l|l|l|}
\hline \multicolumn{7}{|c|}{ able.5: DHF vs Directivity } \\
\hline S.NO & $\mathbf{f}_{\mathbf{O}}(\mathbf{G H Z})$ & $\mathbf{H}(\mathbf{m m})$ & $\boldsymbol{\varepsilon}_{\bar{F}}$ & $\mathrm{D}_{\mathrm{c}}(\mathbf{d B})$ & $\mathrm{D}_{\mathrm{n}}(\mathbf{d B})$ \\
\hline 1 & 3 & 3.79 & 2.2 & 7.91 & 7.81 \\
\hline 2 & 6 & 1.6 & 3.2 & 7.13 & 7.34 \\
\hline 3 & 9 & 1.26 & 4.2 & 6.89 & 7.1 \\
\hline 4 & 12 & 0.94 & 4.4 & 6.77 & 7.06 \\
\hline 5 & 15 & 0.75 & 6 & 7.05 & 7.05 \\
\hline
\end{tabular}

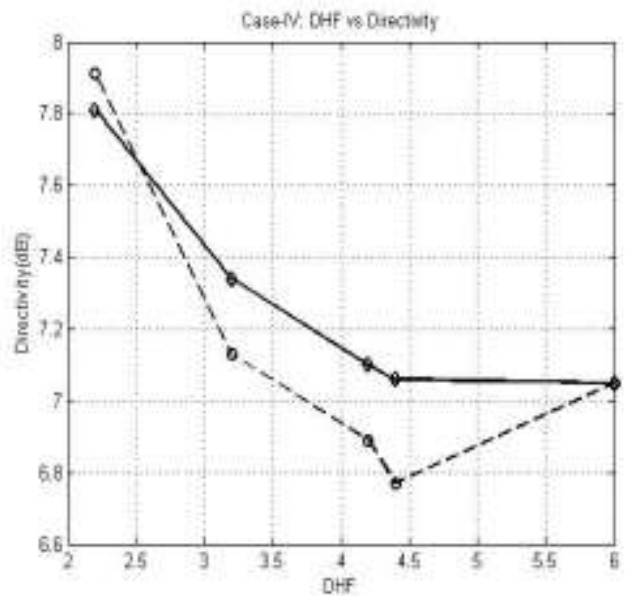

Fig.5: Comparison of Directivities for various frequencies, height of substrate and Dielectric Constant.

NOTE: --O-- is presented conventional formulas of inset fed and $\downarrow$ is presented new formulas of inset fed. 
Case-IV study, gives that the better directivity of Optimized inset than conventional. Based on above four cases study, the design of MSA with variable all parameters such as height and martial of substrate with related to operating frequency. This give optimized results.

\section{Proposed antenna with optimized inset fed:}

By observing all the four cases, newly proposed formulas will get better results than the conventional formulas with perfect matching of impedance between patch and feed line (near $50 \mathrm{ohms}$ ) and Case-IV will get better results compared to other three cases for newly proposed formulas according to size.

Conventional antenna and proposed designed patch details and comparing at $12 \mathrm{GHz}$ Operating frequency, FR4 epoxy as substrate with thickness $0.95 \mathrm{~mm}$ are the length and width of patch are $5.58 \mathrm{~mm}$ and $7.60 \mathrm{~mm}$, feed line length $6.9 \mathrm{~mm}$ and feed line width $1.81 \mathrm{~mm}$. The dimensions of notch define as

Conventional: gap $=0.04 \mathrm{~mm}$, depth $=1.7 \mathrm{~mm}$

Proposed: gap $=0.38 \mathrm{~mm}$, depth $=1.8 \mathrm{~mm}$

The proposed antenna gives better results than conventional, as tabulated below in table- 6 .

Table.6: Conventional vs proposed antenna results.

\begin{tabular}{|l|l|l|l|}
\hline S.NO & TYPE & $\begin{array}{l}\text { GAIN } \\
(\mathbf{d B})\end{array}$ & $\begin{array}{l}\text { DIRECTIVITY } \\
(\mathbf{d B})\end{array}$ \\
\hline 1 & CONVETIONAL & 4.9 & 6.77 \\
\hline 2 & PROPOSED & 5.33 & 7.05 \\
\hline
\end{tabular}

The proposed antenna impedance mismatch decreased as compared with conventional antenna. As shown in figure. 6. In their input resistance is near to $50 \Omega$ in proposed antenna (thick lines) than conventional antenna (dotted lines).

The cross-polarization is also decrease that is shown simulated results below; From Fig.7, the crosspolarization could be decreased that is shown as thick and dark line compared to conventional which is shown as dashed lines.

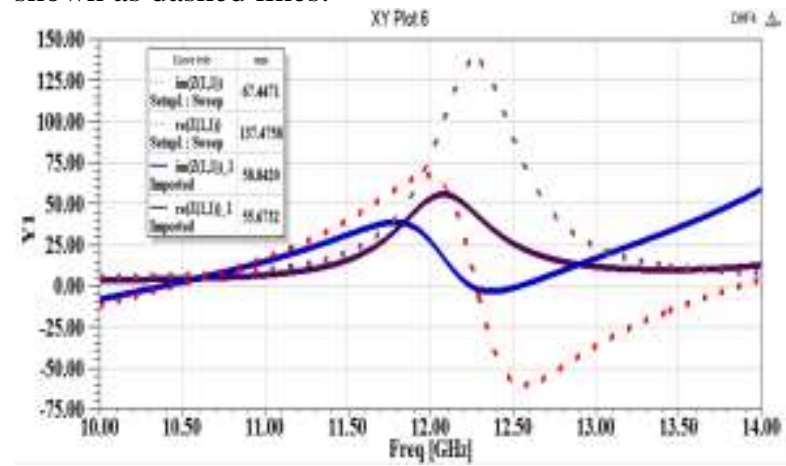

Fig.6: Input impedances of proposed and conventional antennas.

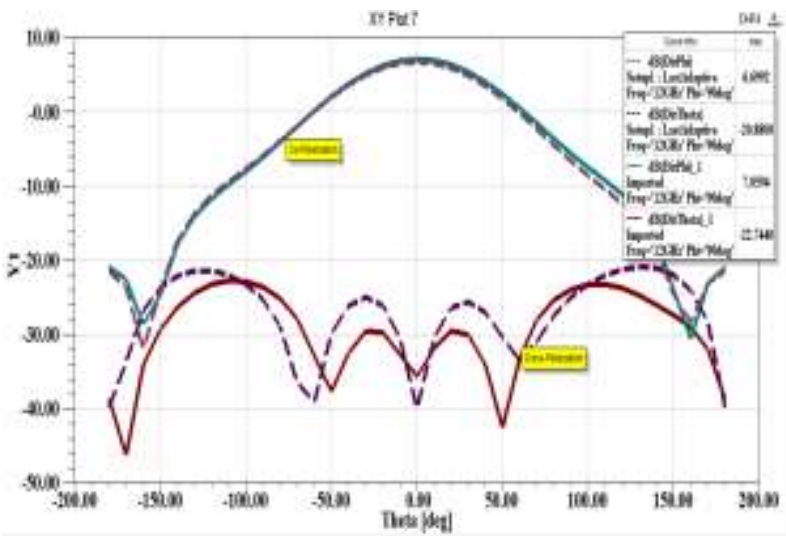

Fig.7: Co and cross-polarizations representation of for comparison of conventional and proposed.

\section{Conclusion}

The impedance mismatch between the patch and feed-line is playing a very big important role as it will be decided the performance of the patch antenna parameters. The impedance mismatch can be decreased by optimized inset fed. Inset fed depended on depth and gap parameters. If changing them the overall capacitance and inductance in between the patch and transmission can be affected. Here defined new formulas (optimized) for depth and gap of inset fed, these formulas are very useful to increase the directivity (antenna parameters) of the patch antenna. By the experimental analysis, is getting the best results in the case-IV. Here by changing height of substrate, operating frequency and dielectric constant of substrate. This can be easily analyzed results of MSA that decrease the return loss, increase gain as well as directivity of the patch. It can be concluded that the newly defined formulas of depth and gap of inset fed have more pronounced effect on performance of antenna parameters.

\section{References}

Authored books:

[1] C. A. Balanis, "Antenna Theory Analysis and Design" 3rd ed. New York, Wiley, 2005, Page no. 727-752.

[2] Paul Wade, Microwave Antenna Book (Chapter 7 Slot Antennas), Online (ex-N1BWT): Paul Wade, 2000-01.

[3] J. R. James and P. S. Hall, "Handbook of Microstrip Antennas" Peter Peregrinus Ltd, 1989,Page No:001-214.

Paper in a journal: [4] E. B. Rosa, "The self and mutual inductances of linear conductors," Bulletin of the Bureau Standards, 1908, Page no. 301-305.

Paper in a journal: [5] D. M. Pozar, "Input impedance and mutual coupling of Rctangular micro strip 
antennas, " IEEE Trans. Antennas Propag, vol. 30, no. 6, Page no. 1191-1196, Nov. 1982.

Paper in a journal: [6] L. I. Basilio, M. A. Khayat, J. T. Williams and S. A. Long, "The Dependence of the Input Impedance on Feed Position of Probe and Micro strip Line- fed Patch Antennas," IEEE Transactions On Antennas And Propagation, Vol. 49, No. 1, January 2001.

Paper in a journal: [7] Akshay Kumar, Amarveer Singh, Ekambir Sidhu, "Equivalent Circuit Modelling of Micro strip Patch Antenna(MPA) Using Parallel LCR Circuits," IJETT , Volume 25, Page no. 183185, Number 4- July 2015.

Paper in a journal: [8] S. C.Wu, N. G. Alexopoulos, and O. Fordham, "Feeding structure contribution to radiation by patch antennas with rectangular boundaries," IEEE Trans. Antennas Propag., vol. 40, no. 10, Page no. 1245-1249, Oct. 1992.

Paper in a journal: [9] Parul Bansal , Ekambir Sidhu , Sonia Goyal, "Equivalent Circuit Modeling Of Slotted micro strip Patch Antenna," IJRET, Volume: 03 Issue: 05, Page no. 444-447, May-2014.

Paper in a journal: [10] Ramesh Garg and V. S. Reddy, "Edge Feeding of Microstrip Ring Antennas" IEEE Trans. Antennas Propag, vol. 51, no.8, Page no. 1941-1946, Aug. 2003.

Paper in a journal: [11] D. L. Sengupta, "The Transmission line model for rectangular patch antenna," IEEE International Symposium Digest, Antennas and Propagation, Vol. 1, Page no. 158161,May 1983.

Paper in a journal: [12] Xiao Zhang and Lei Zhu, "Patch Antennas With Loading of a Pair of Shorting Pins Towar Flexible Impedance Matching and Low Cross Polarization " IEEE Transactions On Antennas\& Propagation, Vol. 64, No. 4, Page no. 1226-1233, April 2016.

Paper in a journal: [13] Nagendra kushwaha and Raj Kumar, " Study of Different Shape Electromagnetic Band Gap (EBG) Structures for Single and Dual band Applications", Journal of Microwaves, Optoelectronics and Electromagnetic Applications, Vol. 13, No. 1, June 2014,pp.16-30.

Paper in a journal: [14] Md. Shahidul Alam, Norbahiah Misran, Baharudin Yatim, and Mohammad Tariqul Islam, "Development of Electromagnetic Band Gap Structures in the Perspective of Microstrip Antenna Design", International Journal of Antennas and Propagation Volume 2013, Article ID 507158, pp. 1-22.

Paper in a journal: [15] Peter Kovacs, Tomas URBANEC, "Electromagnetic Band Gap Structures:Practical Tips and Advice for Antenna Engineers", Radioengineering, Vol. 21, No. 1, April 2012, pp. 414-421.
Paper in a journal: [16] S.Yamini and B.Panjavarnam, "Microstrip Patch Antenna Integrated With EBG", IEEE conference, 2017 , pp. 41-45.

Paper in a journal: [17] Jing Liang and H. Y. David Yang, "Microstrip Patch Antennas on Tunable Electromagnetic Band-Gap Substrates", IEEE Transactions On Antennas And Propagation, Vol. 57, No. 6, June 2009, pp.1612-1617.

Paper in a journal: [18] Nazish Irfan, Mustapha C. E. Yagoub and Khelifa Hettak, "Design of a Micro strip -Line-Fed Inset Patch antenna for RFID Applications," IACSIT International Journal of Engineering and Technology, Vol. 4, No. 5, Page no. 558-561, October 2012.

Paper in a journal: [19] Y. Hu, D. R. Jackson, J. T. Williams, S. A. Long and V. R. Komanduri, "Characterization of the input of the inset-fed rectangular micro strip antenna," IEEE Trans. Antennas Propagation., vol. 56, no. 10, Page no. 3314-3318, Oct. 2008.

Paper in a journal: [20] M. A. Matin and A. I. Sayeed, " A Design Rule for Inset-fed Rectangular Micro strip patch antenna, "Wseas Transactions on comunications, Issue-1, Volume-9, Page no. 63-72, January 2010.

Paper in a journal: [21] M. Ramesh and YIP KB," Design Formula for Inset Fed Micro strip Patch Antenna," Journal of Microwaves and Optoelectronics, Vol. 3, Issue . 3, Page no. 5-10, December 2003.

Paper in a journal: [22] Basheer Ali Sheik, P. V. Sridevi and P.V. Ramaraju "Enhancement of Gain and Directivity in Inset Fed Patch Antenna Using HFSS" IJCTA, vol 10, Page no. 91-105, Nov 26, 2016.

Paper in a journal: [23] Y. Hu, D. R. Jackson, J. T. Williams, S. A. Long, and V. R. Komanduri, "Characterization of the input impedance of the insetfed rectangular microstrip antenna," IEEE Trans. Antennas Propag., vol. 56, no. 10, pp. 3314-3318, Oct. 2008.

Paper in a journal: [24] S. T. Fang, K. L. Wong, and T. W. Chiou, "Bandwidth enhancement of insetmicrostrip-line-fed equilateral-triangular microstrip antenna," Electron Lett., vol. 34, pp. 2184-2186, Nov. 1998. 